\title{
Editor's Commentary: The Letter to the Other Editor
}

\author{
Markus K. Heinemann ${ }^{1}$ \\ ${ }^{1}$ Department of Cardiac, Thoracic and Vascular Surgery, University \\ Hospital Mainz, Mainz, Germany \\ Thorac Cardiovasc Surg 2016;64:364-365.
}

Address for correspondence Markus K. Heinemann, MD, PhD, Department of Cardiac, Thoracic and Vascular Surgery, Universitaetsmedizin Mainz, Langenbeckstr. 1, \# 505, D 55131 Mainz, Germany (e-mail: heinemann@uni-mainz.de).

Prof. Boening turned to Yours Truly, the Editor of the journal of his scientific society. After some deliberation I decided to accept the Letter for the following reasons:

The original article will very probably belong to the most read and most cited ones of the NEJM this year. It deals with a field where not only strictly medical issues are under discussion. The commentator comes from Germany, the uncrowned world champion in transcatheter valve implantation. The concerns raised are substantial and must be known to the public to enable a sound judgment of the setup of the study reported, its potential drawbacks, and to put its conclusions into perspective.

So here it is: the Letter-to-the-Other-Editor. It may be a somewhat unusual construct, but in the interest of the fundamental right to freedom of expression and of open scientific discussion we have opened this door which must not be abused in the future.

We'll also make sure that Jeffrey Drazen will get his letter in the end.

\section{Reference}

1 The New England Journal of Medicine Web site. Available online at http://www.nejm.org/page/author-center/letter-submission. Accessed June 2, 2016 received

June 2, 2016

accepted

June 3, 2016

published online

June 24, 2016 (c) 2016 Georg Thieme Verlag KG Stuttgart · New York
DOI http://dx.doi.org/ 10.1055/s-0036-1584885. ISSN 0171-6425. 


\section{"Transcatheter or Surgical Aortic Valve Replacement in Intermediate-Risk Patients"-Comparing Apples and Oranges?}

\author{
Andreas Böning ${ }^{1}$ \\ ${ }^{1}$ Department of Cardiovascular Surgery, Justus-Liebig University \\ Giessen, Giessen, Germany
}

After I had read the paper by Leon et $\mathrm{al}^{1}$ reporting the results of the PARTNER II study comparing transcatheter and surgical aortic valve replacement (SAVR) in intermediate-risk patients, published in the New England Journal of Medicine (NEJM), I saw several potential problems with this study. Therefore, I wrote a letter to the editor of the NEJM, which was rejected because I had submitted it outside of the timeframe of 3 weeks given by the journal. Because I think that this publication ${ }^{1}$ cannot be left uncommented, I am now sending this letter to you in the hope of a publication in The Thoracic and Cardiovascular Surgeon.

\section{Original Text}

The results of the PARTNER II study have long been awaited and insights of this study will most probably have an impact on the phrasing of guidelines and consequently may open the door for transcatheter aortic valve procedures in intermediate-risk patients. Although the conclusion of the study is clear (noninferiority of one over the other method after a 2-year follow-up), transcatheter aortic valve replacement (TAVR) will rapidly spread out and replace SAVR in this patient group.

In particular, two diagrams of Fig. 1 (panel $C$ and D) caught my attention and will most probably be cited very frequently in the future. These two diagrams show a comparison between SAVR and transfemoral (TF) TAVR cohorts, which struck me as being rather unfair: Within the TAVR group, there seems to be a clear decision bias in favor of TF-TAVR and against transatrial (TA) TAVR, resulting in a selection of patients with the highest risk for the TA-TAVR group. To exclude these "highest-risk" patients in the analysis and comparing the lowest-risk group (TF-TAVR) with surgery is not appropriate as it results in a clear bias of the study and reminds one of cherry picking.

Moreover, a second aspect of the patient selection in the PARTNER II study deserves attention: Within the surgical group, nearly one-quarter of the patients were not SAVR-only candidates, but had concomitant procedures (14.5\% coronary artery bypass grafting, $9.1 \%$ valve or aortic procedures) in
Address for correspondence

Prof. Dr. Andreas Boening, MD, Department of Cardiovascular Surgery, University Hospital Giessen, Rudolf-Buchheim-Str. 7, 35392 Giessen, Germany (e-mail: andreas.boening@chiru.med.uni-giessen.de)

contrast to the TAVR group. However, it is well known and obvious that combination procedures are more complex and therefore have a different risk profile than SAVR alone, resulting in a higher short and midterm mortality. Thus, the analysis compares apples with several oranges! With the knowledge that $23.6 \%$ of the patients in the SAVR group underwent additional procedures, the surprisingly high surgical mortality of "SAVR" in this analysis can be easily explained. To avoid comparing apples and oranges it would have been more accurate to include only isolated SAVR procedures in the analysis and present these results. Interestingly, another recently published paper also took advantage of the surgical data from the PARTNER II trial for a comparison between TAVR and SAVR for the Sapien 3 device. ${ }^{2}$ In this study, the fact that a substantial percentage of patients in the SAVR group had concomitant procedures was not even mentioned. This is remarkable, as in my view, the Sapien 3 device so far has shown an impressive performance in various studies and settings and by no means should not have withstood a comparison with a "SAVR-only" cohort.

Finally, it should be mentioned that this trial was designed and surveyed by the commercial manufacturer of the respective transcatheter valve and patients were adjudicated into the respective trial groups by members of the executive and steering committee of the PARTNER II trial, which seems rather questionable as recently referred to in the NEJM itself. ${ }^{3}$

\section{References}

1 Leon MB, Smith CR, Mack MJ, et al; PARTNER 2 Investigators. Transcatheter or surgical aortic-valve replacement in intermediate-risk patients. N Engl J Med 2016;374(17):1609-1620

2 Thourani VH, Kodali S, Makkar RR, et al. Transcatheter aortic valve replacement versus surgical valve replacement in intermediate-risk patients: a propensity score analysis. Lancet 2016;387(10034): 2218-2225

3 Anderson ML, Chiswell K, Peterson ED, Tasneem A, Topping J, Califf RM. Compliance with results reporting at ClinicalTrials.gov. N Engl J Med 2015;372(11):1031-1039 